\title{
Curcumin decreases epithelial-mesenchymal transition by a Pirin-dependent mechanism in cervical cancer cells
}

\author{
VICTOR AEDO-AGUILERA ${ }^{1,2 *}$, DIEGO CARRILLO-BELTRÁN ${ }^{2 *}$, GLORIA M. CALAF ${ }^{1,3}$, \\ JUAN P. MUÑOZ ${ }^{1,2}$, NAHIR GUERRERO ${ }^{2}$, JULIO C. OSORIO ${ }^{2}$, JULIO C. TAPIA ${ }^{2}$, \\ OSCAR LEÓN ${ }^{4}$, HECTOR R. CONTRERAS ${ }^{2}$ and FRANCISCO AGUAYO FI, $^{1,2}$ \\ ${ }^{1}$ Instituto de Alta Investigación, Universidad de Tarapacá, Arica 8097877; ${ }^{2}$ Departamento de Oncología Básico Clínica, \\ Facultad de Medicina, Universidad de Chile, Santiago 8380453, Chile; ${ }^{3}$ Center for Radiological Research, \\ Columbia University Medical Center, New York, NY 10032, USA; ${ }^{4}$ Programa de Virología, \\ Instituto de Ciencias Biomédicas (ICBM) and ${ }^{5}$ Advanced Center for Chronic Diseases (ACCDiS), \\ Facultad de Medicina, Universidad de Chile, Santiago 8380453, Chile
}

Received November 5, 2018; Accepted June 7, 2019

DOI: $10.3892 /$ or.2019.7288

\begin{abstract}
Curcumin is a natural antioxidant polyphenol, which decreases epithelial-mesenchymal transition (EMT) and cell migration in cervical cancer cells. However, the mechanism by which such a decrease occurs is unclear. It is well established that cervical cancer can be caused by high-risk human papillomavirus (HPV), which overexpresses E6 and E7 oncoproteins. Recent findings have suggested that viral oncoproteins regulate the expression of Pirin, which is an oxidative stress sensor involved in EMT and cell migration. Molecular markers associated with EMT, pirin and HPV were evaluated using reverse transcription-reverse quantitative PCR and western blotting. In addition, the migratory ability of cells was evaluated using a Transwell assay. In order to evaluate the role of Pirin in curcumin-mediated inhibition of EMT, SiHa cervical carcinoma cells, which contain two integrated copies of HPV16, were exposed to curcumin. Cell migration, and the expression levels of EMT biomarkers and the pirin protein, which is a product of the PIR gene, were subsequently evaluated. The results demonstrated a significant decrease in EMT following exposure to $20 \mu \mathrm{M}$ curcumin for $72 \mathrm{~h}$. This finding was supported by a decrease in the protein expression levels of $\mathrm{N}$-cadherin, Vimentin and Slug. Furthermore, it was observed that PIR expression and Pirin protein levels were significantly decreased when SiHa cells were exposed to curcumin. Subsequently, to
\end{abstract}

Correspondence to: Dr Francisco Aguayo, Departamento de Oncología Básico Clínica, Facultad de Medicina, Universidad de Chile, Independencia 1027, Santiago 8380453, Chile

E-mail:faguayo@med.uchile.cl

*Contributed equally

Key words: curcumin, cervical cancer, Pirin, epithelial-mesenchymal transition, papillomavirus analyze the effects of Pirin on EMT, SiHa cells were transfected with a small interfering RNA (siRNA) to knockdown PIR. A significant increase in E-cadherin mRNA expression and a decrease in $\mathrm{N}$-cadherin protein expression were observed. In addition, a similar decrease was observed when SiHa cells were exposed to both PIR siRNA and curcumin. Finally, a significant decrease in SiHa cell migration was observed in the presence of $20 \mu \mathrm{M}$ curcumin compared with in the control group. These findings suggested that curcumin may decrease EMT, at least in part by a Pirin-dependent mechanism. Therefore, Pirin protein may be an important pharmacological target for cervical cancer treatment.

\section{Introduction}

Curcumin, also known as diferuloylmethane, is a natural hydrophobic molecule derived from Curcuma longa (also known as turmeric). The structure of curcumin is comprised of three chemical entities: Two aromatic ring systems containing o-methoxy phenolic groups, connected by a seven-carbon linker consisting of an $\alpha, \beta$-unsaturated $\beta$-diketone moiety (1-3). Curcumin is a common food additive used as a spice and a coloring agent (4). This compound has a particularly good safety profile; its toxicity and tolerability have been tested, and a previous study revealed that it is highly tolerable at doses up to $12 \mathrm{~g}$ /day in patients, with no curcumin-related toxicities, due to its low bioavailability (5-7).

It has been reported that curcumin is able to block the nuclear factor $(\mathrm{NF})-\kappa \mathrm{B}$ pathway, which is a critical mediator of intracellular signaling that has been linked to proinflammatory signals that control the expression of a vast array of genes involved in immune and stress responses (8). Notably, this suppression is mediated by numerous inflammatory stimuli through inhibition of IKK $\alpha$ kinase. It has also been reported that the increased levels of tumor necrosis factor- $\alpha$, interleukin (IL)- 6 and IL-8 in a model of acute kidney injury are significantly reduced by curcumin treatment (2). The primary role of curcumin as an antioxidant is to intercept peroxyl free radicals formed during lipid 
peroxidation. This prevents free-radical chain reactions which induce deterioration of the lipid membrane (9). Furthermore, a previous study indicated that the enhancement of apoptosis induced by high doses of curcumin is regulated by antioxidants, such as N-acetyl-1-cysteine (10). Previous studies demonstrated that curcumin prevents several types of cancer $(3-5,11,12)$. In addition, curcumin has been reported to possess anti-invasive properties and is able to interfere with the epithelial-mesenchymal transition (EMT) (13). During EMT, cells shift from an epithelial phenotype towards a mesenchymal phenotype, modifying the expression profile of some adhesion molecules and allowing cells to adopt invasive, migratory behaviors (14).

Cervical cancer is the fourth most common type of cancer in women worldwide and is commonly caused by sexually acquired infection with high-risk human papillomavirus (HR-HPV) (15). Two types of HR-HPV (HPV16 and 18) cause $70 \%$ of cervical cancer cases and precancerous cervical lesions (16). HR-HPV E6 and E7 oncoproteins are overexpressed in cervical carcinoma; this is principally mediated by integration of the virus into the host genome (17). These oncoproteins are considered to be the primary carcinogenic factors in cervical cancer cells. E6 protein binds to tumor suppressor protein $\mathrm{p} 53$, and causes its ubiquitination and proteolysis via the proteasome pathway, whereas E7 protein inactivates the retinoblastoma protein by inducing its degradation. Therefore, E6 and E7 oncogenes are strongly involved in cell cycle progression and reduced apoptosis, which lead to carcinogenesis $(18,19)$. Our previous study reported that HPV16 E6 and E7 oncoproteins are involved in promoting Pirin gene (PIR) upregulation in epithelial cervical and oral cancer cells. Since the PIR gene encodes for Pirin, an oxidative stress sensor, these previous findings suggested that E6 and E7 are involved in cervical cancer progression through Pirin (20). Pirin is a highly conserved 32-kDa protein assigned to the cupin superfamily of proteins $(21,22)$. Its structure comprises two barrel domains, with an Fe (II) cofactor bound within the cavity of the N-terminal domain (23). Furthermore, it has been reported that Pirin may act as an activator of the NF- $\kappa$ B pathway (24). It has previously been demonstrated that Pirin is involved in EMT regulation, as well as cell migration $(20,25,26)$. There is mounting evidence of a hierarchy that controls the expression of transcriptional regulators of EMT. During development and cancer progression, the contribution of different EMT inducers is dependent on the cellular context (14). Previous findings have suggested that curcumin is able to decrease the levels of HR-HPV E6/E7 in cervical cancer cells (6). The present study revealed that curcumin decreased EMT of cervical cancer cells, at least in part, through a Pirin-dependent mechanism, which in turn may be dependent on HPV16 E6/E7 levels.

\section{Materials and methods}

Cell culture and curcumin treatment. The SiHa (HTB-35) cell line was obtained directly from the American Type Culture Collection. The cells were incubated in RPMI-1640 basal medium (Gibco; Thermo Fisher Scientific, Inc.) supplemented with $10 \%$ fetal bovine serum (FBS; Hyclone; GE Healthcare) and antibiotics (100 U/ml penicillin, $100 \mathrm{~g} / \mathrm{ml}$ streptomycin) at $37^{\circ} \mathrm{C}$ in an atmosphere containing $5 \% \mathrm{CO}_{2}$. Cells were serum-depleted for $24 \mathrm{~h}$ and were treated with $20 \mu \mathrm{M}$ curcumin
(Sigma-Aldrich; Merck KGaA) or DMSO for $72 \mathrm{~h}$ at $37^{\circ} \mathrm{C}$ in an atmosphere containing $5 \% \mathrm{CO}_{2}$ in a humidified incubator.

Cell viability assay. Cells were grown to $80 \%$ confluence and were incubated with serum-free RPMI-1640 medium in 60-mm plates for $24 \mathrm{~h}$. The cells were then trypsinized with EDTA-trypsin mixture (Invitrogen; Thermo Fisher Scientific, Inc.) and counted using trypan blue exclusion staining with a Neubauer chamber (27). For the MTS assay, cells were cultured to $80 \%$ confluence in a 96 -well flat-bottomed microtiter plate with RPMI-1640 medium and were treated with $20 \mu \mathrm{M}$ curcumin for 24-96 h; DMSO was used as a control. Finally, $20 \mu \mathrm{l}$ MTS (Promega Corporation) was added to each well, the plate was incubated for $3 \mathrm{~h}$ at $37^{\circ} \mathrm{C}$ and absorbance was measured at $492 \mathrm{~nm}$ using a microplate reader (Biotek Instruments, Inc.).

Knockdown of PIR and E6/E7. Cells at $80 \%$ confluence were serum-depleted for $24 \mathrm{~h}$ and were transfected with $30 \mu \mathrm{M}$ small interfering RNA (siRNA) targeting PIR (cat. no. sc-61359; Santa Cruz Biotechnology, Inc.), HPV16 E6/E7 (cat. no. sc-270423; Santa Cruz Biotechnology, Inc.) and Silencer ${ }^{\mathrm{TM}}$ Select Negative Control No. 1 siRNA (cat. no. 4390843; Invitrogen; Thermo Fisher Scientific, Inc.) for $24 \mathrm{~h}$ at $37^{\circ} \mathrm{C}$ in an atmosphere containing $5 \% \mathrm{CO}_{2}$ using Lipofectamine $^{\circledR} 2000$ (Invitrogen; Thermo Fisher Scientific, Inc.) according to the manufacturer's protocol. RNA and proteins were collected for subsequent analyses.

RNA extraction and cDNA synthesis. RNA was isolated from cells using TRIzol ${ }^{\circledR}$ reagent (Invitrogen; Thermo Fisher Scientific, Inc.) according to the manufacturer's protocol. Following chloroform purification and isopropanol precipitation, RNA was suspended in DEPC-water and stored at $-80^{\circ} \mathrm{C}$. The RNA was treated with RQ1 RNase-free DNase (Promega Corporation) at $37^{\circ} \mathrm{C}$ for $120 \mathrm{~min}$ and was incubated with RQ1 DNase Stop Solution for $10 \mathrm{~min}$. cDNA was prepared in a $20-\mathrm{ml}$ reaction volume containing DNAse-treated RNA (1 $\mu \mathrm{g}), 1$ unit RNAse inhibitor (Promega Corporation), $0.4 \mu \mathrm{g} / \mathrm{ml}$ random primers (Promega Corporation), $2 \mathrm{mM}$ dNTP (Promega Corporation) and 10 units Moloney Murine Leukemia Virus reverse transcriptase (Promega Corporation). The reaction mixture was incubated for $1 \mathrm{~h}$ at $37^{\circ} \mathrm{C}$.

Quantitative polymerase chain reaction ( $q P C R)$. cDNA was subjected to qPCR quantification of gene expression with specific primers (Table I) using a Rotor-Gene 6000 system (Qiagen, Inc.) under the following conditions: $95^{\circ} \mathrm{C}$ for 10 min followed by 40 cycles of denaturation at $95^{\circ} \mathrm{C}$ for $15 \mathrm{sec}$, annealing at $55^{\circ} \mathrm{C}$ for $20 \mathrm{sec}$ and extension at $72^{\circ} \mathrm{C}$ for $20 \mathrm{sec}$. To obtain the dissociation curve, the temperature was increased from 70 to $90^{\circ} \mathrm{C}\left(0.5^{\circ} \mathrm{C}\right.$ increase at each step). The reaction was performed using $2 \mathrm{X}$ SYBR Green Master Mix (Bioline), $0.4 \mu \mathrm{M}$ primer pair, $10.5 \mu \mathrm{l}$ RNase-free water and $1 \mu \mathrm{l}$ cDNA in a $25-\mu 1$ final volume. Specific primers and amplification conditions were adjusted for each RNA sequence. Standard curves for each gene were generated independently by preparing 10 -fold serial dilutions of DNA amplicons. The relative copy number of each sample was calculated through the $2^{-\Delta \Delta \mathrm{Cq}}$ method using Rotor-Gene software version 4 (Qiagen, Inc.) (28). Endogenous $\beta$-actin mRNA levels were 
Table I. Primer sequences.

\begin{tabular}{|c|c|c|c|}
\hline Gene & Product size (bp) & Primer sequence & Annealing temperature, ${ }^{\circ} \mathrm{C}$ \\
\hline E6 & 96 & $\begin{array}{l}\text { F: 5'-CTGCAAGCAACAGTTACTGCGA-3' } \\
\text { R:5'-TCACACACTGCATATGGATTCCC-3' }\end{array}$ & 58 \\
\hline E7 & 120 & $\begin{array}{l}\text { F: 5'-CAATATTGTAATGGGCTCTGTCC-3' } \\
\text { R: 5'-ATTTGCAACCAGAGACAACTGAT-3' }\end{array}$ & 58 \\
\hline E-cadherin & 135 & $\begin{array}{l}\text { F: 5'-GCACCGGTCGACAAAGGACA-3' } \\
\text { R: 5'-AGTCCCAGGCGTAGACCAAGA-3' }\end{array}$ & 58 \\
\hline $\mathrm{N}$-cadherin & 121 & $\begin{array}{l}\text { F: 5'-AAGAACGCCAGGCCAAACAA-3' } \\
\text { R: 5'-TGCAGCTGGCTCAAGTCATA-3' }\end{array}$ & 58 \\
\hline Vimentin & 131 & $\begin{array}{l}\text { F: 5'-GCCCTTGACATTGAGATTGCCA-3' } \\
\text { R: 5'-TCAACCAGAGGGAGTGAATCCA-3' }\end{array}$ & 58 \\
\hline Slug & 117 & $\begin{array}{l}\text { F: 5'-CTCCATTCCACGCCCAGCTAC-3' } \\
\text { R: 5'-AGCCACTGTGGTCCTTGGAG-3' }\end{array}$ & 60 \\
\hline Snail & 84 & $\begin{array}{l}\text { F: 5'-AGGCTCGAAAGGCCTTCAACT-3' } \\
\text { R: 5'-TGTGGCTTCGGATGTGCATCT-3' }\end{array}$ & 60 \\
\hline Zeb1 & 157 & $\begin{array}{l}\text { F: 5'-ACTGCCTGGTGATGCTGAAA-3' } \\
\text { R: 5'-CCCAAACTGCAAGAAACGCT-3' }\end{array}$ & 60 \\
\hline PIR & 131 & $\begin{array}{l}\text { F: 5'-TCAAATTGGACCCAGGAGCC-3' } \\
\text { R: 5'-TCCAAGCACTGCTGTGTGAT-3' }\end{array}$ & 55 \\
\hline
\end{tabular}

F, forward; PIR, pirin; R, reverse; Zeb1, zinc finger E-box binding homeobox 1.

used for normalization of mRNA expression. All reactions were performed in triplicate.

Western blotting. Total protein was extracted from cells with a lysis buffer [20 mM Tris (pH 8.0), 1\% SDS] containing protease inhibitor cocktail (Roche Diagnostics). The cells were incubated at $4^{\circ} \mathrm{C}$ for $1 \mathrm{~h}$, sonicated at $20 \mathrm{kHz}$ for $20 \mathrm{sec}$ on ice and centrifuged at $12,000 \times \mathrm{g}$ for $10 \mathrm{~min}$ at $4^{\circ} \mathrm{C}$. The proteins were quantified using the Pierce Bicinchoninic Acid Protein Assay kit (Pierce; Thermo Fisher Scientific, Inc.) and $30 \mu \mathrm{g}$ protein extract was loaded per well. Proteins were separated by $12 \%$ SDS-PAGE and were then transferred to Hybond-P ECL membranes (Amersham; GE Healthcare) using $20 \mathrm{mM}$ Tris and $150 \mathrm{mM}$ glycine ( $\mathrm{pH} 8.3$ ), in $20 \%$ methanol with semi-dry transfer apparatus (Bio-Rad Laboratories, Inc.). Membranes were then incubated for $2 \mathrm{~h}$ at room temperature with the blocking reagent [5\% bovine serum albumin (AppliChem $\mathrm{GmbH}$ ) in $0.5 \%$ Tris buffered saline/0.1\% Tween-20 (TBST, $\mathrm{pH}$ 7.6)] and were incubated overnight at room temperature with the following primary antibodies: $\beta$-actin (cat. no. ab6276; Abcam), N-cadherin (cat. no. ab98952; Abcam), zinc finger E-box binding homeobox 1 (Zeb1; cat. no. pa520979; Thermo Fisher Scientific, Inc.), Pirin (cat. no. ab51360; Abcam), HPV16 E6 (cat. no. sc-460; Santa Cruz Biotechnology, Inc.), HPV16 E7 (cat. no. sc-6981; Santa Cruz Biotechnology, Inc.), E-cadherin (cat. no. sc-21791; Santa Cruz Biotechnology, Inc.), Slug (cat. no. sc-166476; Santa Cruz Biotechnology, Inc.) and Vimentin (cat. no. sc-6260; Santa Cruz Biotechnology, Inc.), which were diluted 1:1,000 in TBST. Membranes were washed three times in TBST and were then incubated for $1 \mathrm{~h}$ at room temperature with peroxidase-labeled secondary IgG antibodies (anti-mouse cat. no. 554002; BD Pharmingen; BD Biosciences; and anti-rabbit cat. no. sc-2004; Santa Cruz Biotechnology, Inc.), which were diluted 1:2,000 in TBST. After washing three times in TBST, immune complexes were detected using an ECL system (Amersham; GE Healthcare) according to the manufacturer's protocol. For semi-quantitative analysis, ImageJ software version 1.52a (National Institutes of Health) was used.

Cell migration assays. For the three-dimensional migration assay, the bottom side of the upper chamber of a Transwell system (pore size, $8 \mu \mathrm{m}$; Corning, Inc.) was coated with $1 \mu \mathrm{g} / \mathrm{ml}$ fibronectin (cat. no. PHE0023; Gibco; Thermo Fisher Scientific, Inc.) and incubated overnight at $4^{\circ} \mathrm{C}$. A total of 50,000 SiHa cells in supplement-free medium were seeded in the upper chamber, whereas $500 \mu \mathrm{l}$ complete medium was added per well. Cells were then allowed to migrate for $7 \mathrm{~h}$ at $37^{\circ} \mathrm{C}$ in an atmosphere containing $5 \% \mathrm{CO}_{2}$. Migrated cells were fixed and stained for $15 \mathrm{~min}$ at room temperature with $0.5 \% \mathrm{w} / \mathrm{v}$ crystal violet/methanol solution, whereas non-migrated cells were removed using a cotton tip. Migrated cells were counted in eight fields for each experiment using an inverted light microscope.

The wound-healing assay was carried out according to previously reported protocols (29). Briefly, SiHa cells were serum-depleted for $24 \mathrm{~h}$. Subsequently, $4 \times 10^{5}$ cells were seeded in 6-well plates at $90 \%$ cell confluence and exposed to $20 \mu \mathrm{M}$ curcumin for $72 \mathrm{~h}$ at $37^{\circ} \mathrm{C}$. A $10-\mu l$ pipette tip was used to scrape the cell monolayer in a straight line and the cells were washed with PBS and incubated in RPMI medium containing $10 \%$ FBS. Images of the scratches were captured 
A

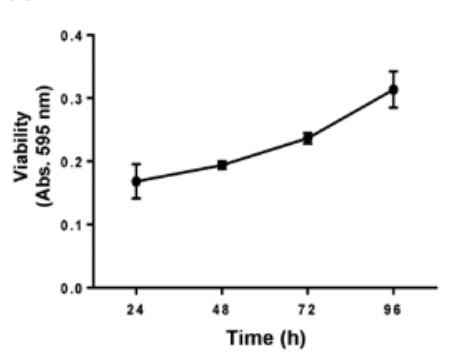

C

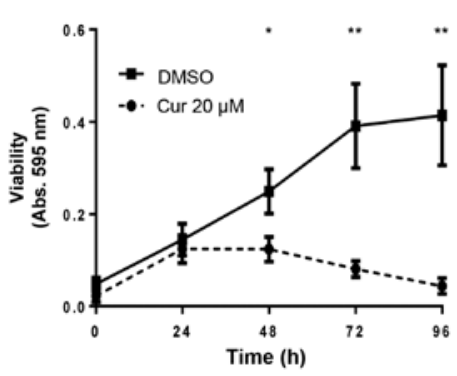

B

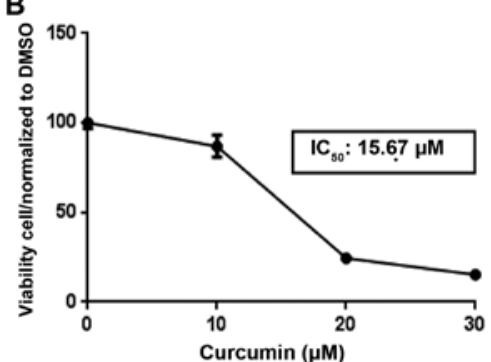

D

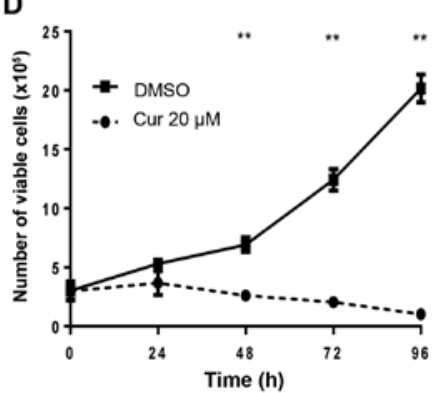

Figure 1. Effects of curcumin on viability of SiHa cells in vitro. (A) SiHa cells were cultured in RPMI (10\% fetal bovine serum) and their viability was evaluated by MTS assay for 24, 48, 72 and $96 \mathrm{~h}$. (B) SiHa cells were exposed to various concentrations of curcumin or DMSO. (C and D) SiHa cells were treated with DMSO or $20 \mu \mathrm{M}$ curcumin. Cell viability was determined after $0,24,48,72$ and $96 \mathrm{~h}$ using (C) MTS assay and (D) cell counting. Data are presented as the mean \pm SEM; average of three independent experiments, conducted in triplicate. ${ }^{*} \mathrm{P}<0.05,{ }^{* *} \mathrm{P}<0.01$ (Mann-Whitney test).

at 0 and $18 \mathrm{~h}$ after wound generation, using a polarized light inverted microscope (magnification, $\mathrm{x} 20$ ).

Statistical analysis. Comparison of means between two groups was performed using a Mann Whitney test, whereas comparisons between multiple groups were performed using one-way ANOVA and Tukey's post hoc test. Data were analyzed using GraphPad Prism version 7 software (GraphPad Software, Inc.). $\mathrm{P}<0.05$ was considered to indicate a statistically significant difference.

\section{Results}

Curcumin decreases viability of cervical cancer cells. The present study used SiHa cervical carcinoma cells, which harbor two copies of HPV16 per cell. A cell viability-time curve is shown in Fig. 1A. In order to determine the appropriate curcumin concentration to be used in subsequent analyses, the viability of SiHa cells in response to various curcumin concentrations was determined by MTS assay (Fig. 1B). The $\mathrm{IC}_{50}$ value was determined to be $15.67 \mu \mathrm{M}$. Considering this concentration as a reference and according to previously reported data $(30,31)$, a concentration of $20 \mu \mathrm{M}$ curcumin was used for subsequent experiments. Cell viability in response to this curcumin concentration was measured by MTS assay (Fig. 1C) and cell counting was conducted using the Trypan blue exclusion assay (Fig. 1D). Although significant cell death was found at 48 and $72 \mathrm{~h}$ (Fig. 1C and D), the curcumin exposure time for subsequent analyses was extended to $72 \mathrm{~h}$.

Curcumin alters E6/E7 and Pirin levels in cervical cancer cells. Firstly, this study confirmed that PIR expression is dependent on E6/E7 in SiHa cells. Accordingly, as shown in Fig. 2A and B, siRNA induced a significant reduction in
A

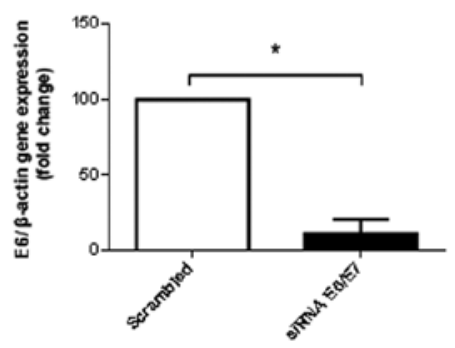

B

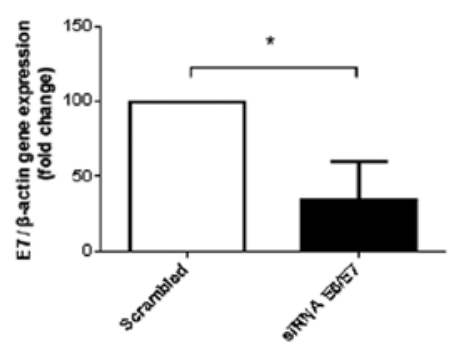

C

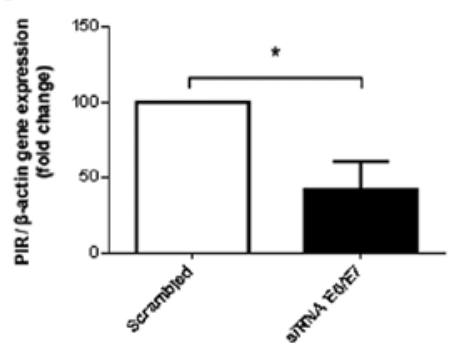

Figure 2. HPV16 E6 and E7 knockdown decreases PIR expression. (A and B) E6 and E7 transcripts evaluated by reverse transcription-quantitative polymerase chain reaction in SiHa cells transfected with scrambled siRNA or siRNA E6/E7. (C) PIR mRNA expression was decreased post-transfection with siRNA E6/E7. Data are presented as the mean \pm SEM; average of three independent experiments, conducted in triplicate. ${ }^{*} \mathrm{P}<0.05$ (Mann-Whitney test). 
A

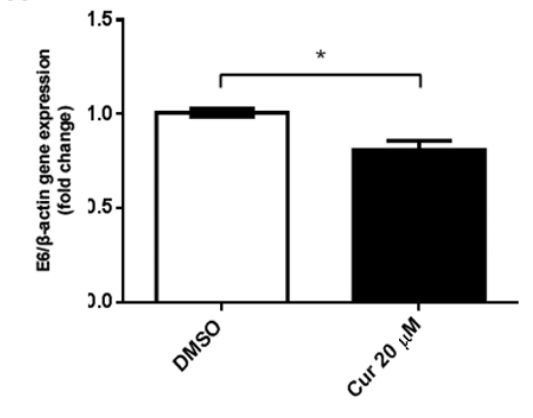

a

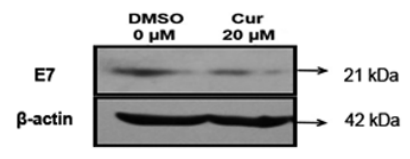

b

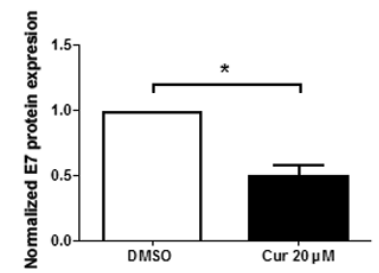

B

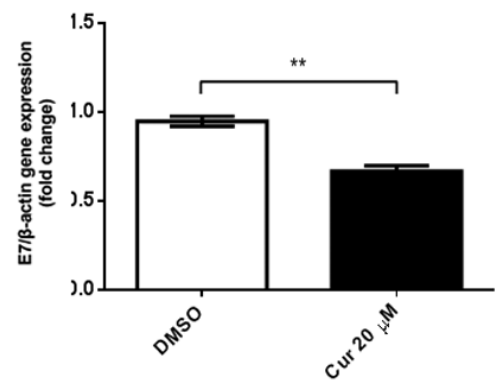

D a

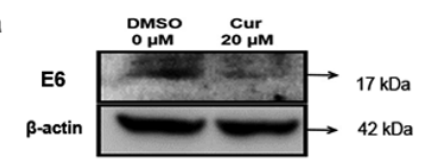

b

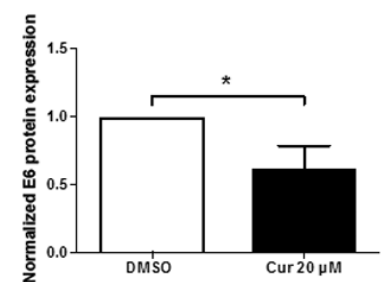

Figure 3. Effects of curcumin on E6 and E7 gene and protein expression levels. SiHa cells were treated with DMSO or $20 \mu \mathrm{M}$ curcumin for $72 \mathrm{~h}$. mRNA extracted at $72 \mathrm{~h}$ underwent reverse transcription-quantitative polymerase chain reaction with primers for (A) E6 and (B) E7. The results were normalized to $\beta$-actin. $(\mathrm{C}-\mathrm{a}$ and D-a) After $72 \mathrm{~h}$, protein extracts underwent western blotting with antibodies against E6, E7 and $\beta$-actin. (C-b and D-b) Densitometric analysis of western blots. Data are presented as the mean \pm SEM; average of three independent experiments, conducted in triplicate. ${ }^{*} \mathrm{P}<0.05,{ }^{* *} \mathrm{P}<0.01(\mathrm{Mann}-\mathrm{Whitney}$ test $)$.

A

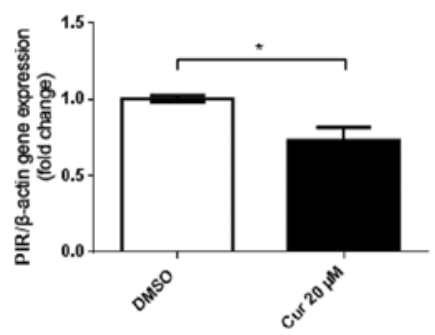

B

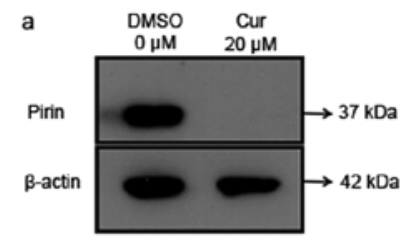

b

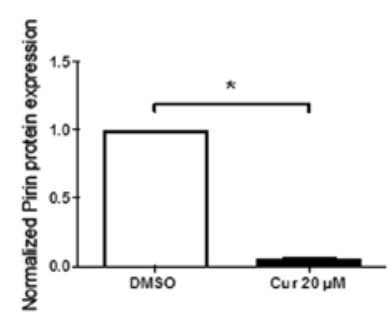

Figure 4. Effects of curcumin on Pirin gene and protein expression levels. SiHa cells were treated with DMSO and $20 \mu \mathrm{M}$ curcumin for $72 \mathrm{~h}$. (A) RNA extracted at $72 \mathrm{~h}$ underwent reverse transcription-quantitative polymerase chain reaction with primers for PIR. The results were normalized to $\beta$-actin (B-a) After $72 \mathrm{~h}$, protein extracts underwent western blotting with antibodies against Pirin and $\beta$-actin. (b) Densitometric analysis of western blots. Data are presented as the mean \pm SEM; average of three independent experiments, conducted in triplicate. ${ }^{*} \mathrm{P}<0.05$ (Mann-Whitney test). PIR, pirin gene. the mRNA expression levels of E6 and E7. In addition, the mRNA expression levels of PIR were significantly decreased in response to E6/E7 knockdown (Fig. 2C). To determine the effects of curcumin on alterations in E6 and E7 gene expression, $\mathrm{SiHa}$ cells were exposed to $20 \mu \mathrm{M}$ curcumin for $72 \mathrm{~h}$. Firstly, it was demonstrated that curcumin induced a significant decrease in endogenous E6 and E7 mRNA expression levels (Fig. 3A and B). A significant decrease in E6 and E7 protein expression was also observed in response to curcumin (Fig. 3C and D). In addition, the effects of curcumin exposure on the mRNA and protein expression levels of Pirin were analyzed. A significant decrease in PIR mRNA expression (Fig. 4A) and Pirin protein expression (Fig. 4B) was detected following exposure to $20 \mu \mathrm{M}$ curcumin for $72 \mathrm{~h}$. Taken together, E6 and E7 may regulate Pirin in SiHa cells, whereas curcumin may decrease the levels of E6/E7 and Pirin in these cells.

Pirin promotes EMT in cervical cancer cells. To determine whether knockdown of PIR affects EMT, cells were transfected with a siRNA. Western blotting was initially performed to confirm the efficiency of PIR siRNA. As shown in Fig. 5A, a significant decrease in Pirin protein expression was revealed. Subsequently, a significant increase in the mRNA expression levels of E-cadherin was observed (Fig. 5B) following PIR knockdown, although it should be noted that the mRNA expression levels of $\mathrm{N}$-cadherin and Vimentin were not detected by RT-qPCR (data not shown). The increase in E-cadherin expression suggested that dependence may exist between Pirin and EMT. Subsequently, PIR was knocked 
A
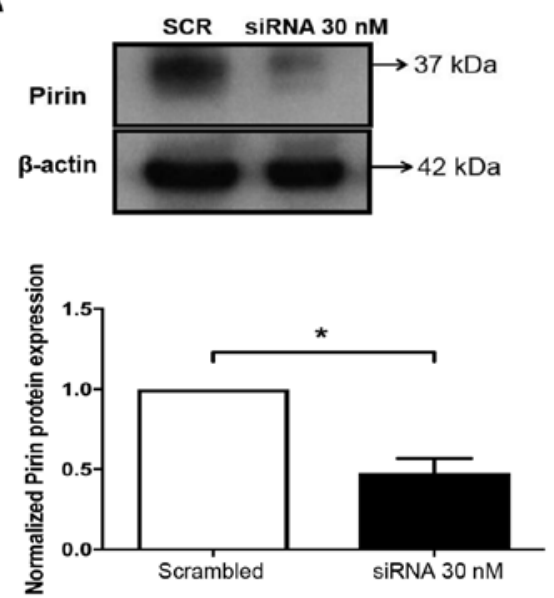

B

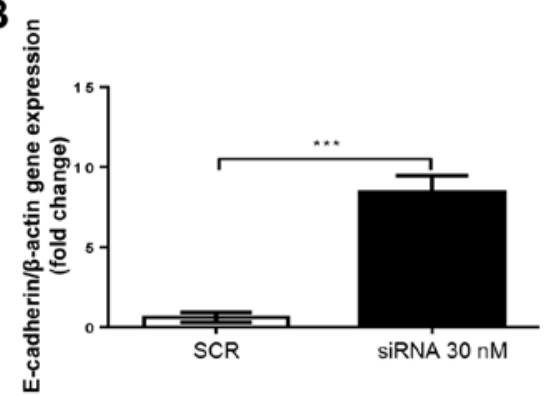

C
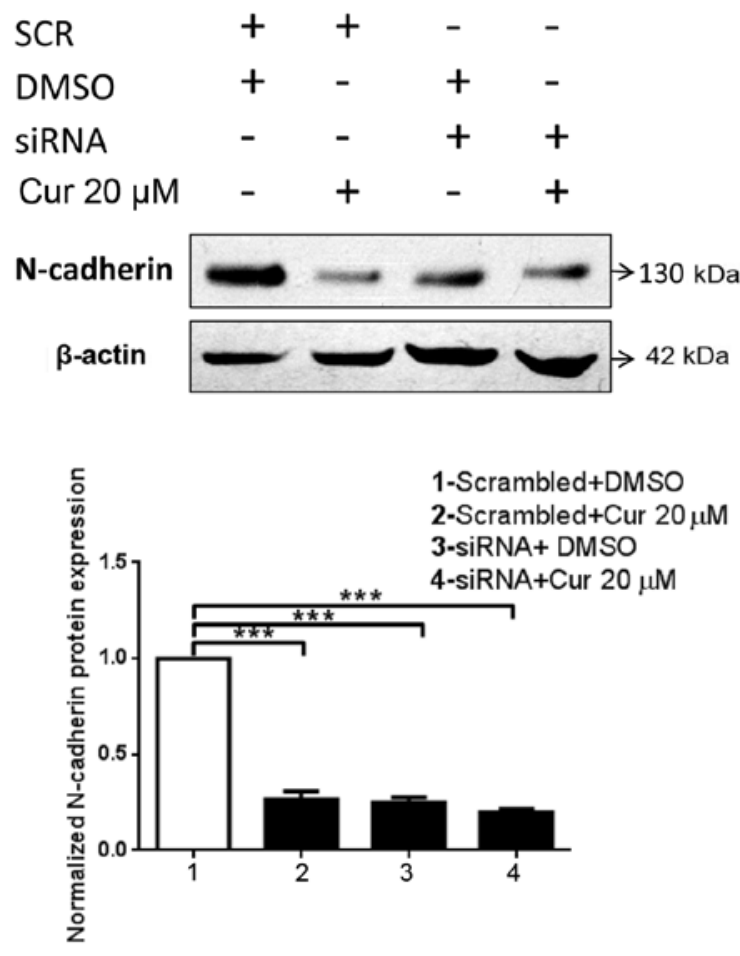

Figure 5. Effect of a siRNA on Pirin expression and the mRNA and protein expression levels of epithelial-mesenchymal transition markers. SiHa cells were transfected with $30 \mathrm{nM}$ PIR or scrambled siRNA for $24 \mathrm{~h}$. (A) Protein extracts obtained at $72 \mathrm{~h}$ were used for western blotting with antibodies against Pirin and $\beta$-actin, and densitometric analysis of the bands was conducted. (B) RNA extracted at 24 h underwent reverse transcription-quantitative polymerase chain reaction with primers for E-cadherin; findings were normalized to $\beta$-actin. ${ }^{*} \mathrm{P}<0.05$ and ${ }^{* * * *} \mathrm{P}<0.001$ (Mann-Whitney test). (C) SiHa cells were transfected with $30 \mathrm{nM}$ PIR or scrambled siRNA for $24 \mathrm{~h}$, and were then treated with DMSO or curcumin $(20 \mu \mathrm{M})$ for $72 \mathrm{~h}$. Protein extracts obtained at $72 \mathrm{~h}$ were used for western blotting with antibodies against $\mathrm{N}$-cadherin and $\beta$-actin, and densitometric analysis of bands was conducted. ${ }^{* * *} \mathrm{P}<0.001$ (ANOVA). Data are presented as the mean \pm SEM; average of three independent experiments, conducted in triplicate. PIR, pirin gene; SCR, scrambled; siRNA, small interfering RNA.

down and SiHa cells were exposed to $20 \mu \mathrm{M}$ curcumin for $72 \mathrm{~h}$. In the PIR siRNA + DMSO group, the protein expression levels of $\mathrm{N}$-cadherin were significantly decreased (Fig. 5C). Furthermore, $\mathrm{N}$-cadherin expression was also decreased in the scrambled siRNA + curcumin and PIR siRNA + curcumin groups, suggesting that both curcumin and Pirin may be involved in $\mathrm{N}$-cadherin downregulation.

Curcumin decreases EMT. The effects of curcumin on EMT were evaluated; the epithelial marker E-cadherin was detected. The mRNA expression levels of E-cadherin were increased (Fig. 6A); however, the protein expression levels were not affected by $20 \mu \mathrm{M}$ curcumin (Fig. 6B). In addition, the expression levels of the mesenchymal markers N-cadherin (Fig. 6C), Vimentin (Fig. 6D), Slug (Fig. S1A) and Zeb1 (Fig. S1B) were detected; the protein expression levels of all of these markers were reduced by $\geq 40 \%$ in response to curcumin. Finally, the mRNA expression levels of Zeb1 (Fig. S1B) and Snail (Fig. S1C) were increased in response to curcumin. The discrepancy between the mRNA and protein expression levels of Zeb1 may be due to changes induced by curcumin at the post-translational level; notably, mechanisms of protein degradation may have been induced, which affected EMT-related proteins. These observations suggested that curcumin may induce a decrease in $\mathrm{SiHa}$ cell EMT.
Curcumin exposure decreases cell migration. Cell migration was evaluated in $\mathrm{SiHa}$ cells exposed to curcumin using Transwell and wound healing assays. As shown in Fig. 7A, a significant decrease in cell migration was observed following exposure to $20 \mu \mathrm{M}$ curcumin for $72 \mathrm{~h}$. To further confirm these results, a wound-healing assay was conducted. As shown in Fig. 7B, it was confirmed that curcumin reduced migration of SiHa cells.

\section{Discussion}

Curcumin has previously been described as an inhibitor of carcinogenesis $(13,32)$ and as a regulator of EMT $(33)$; however, the mechanism by which this polyphenolic compound regulates EMT has not been established. Therefore, this study proposed a mechanism to explain this issue in cervical cancer cells. The SiHa cell line, which harbors two integrated copies of HPV16 (34), was exposed to $20 \mu \mathrm{M}$ curcumin for $72 \mathrm{~h}$; this curcumin concentration has been supported by previous reports $(30,31)$. In addition, a significant decrease in E6 and E7 was observed in cells exposed to curcumin. This finding is in accordance with the findings of previous studies, in vitro (6) and in vivo (12).

Pirin is a well-known oxidative stress sensor; however, its specific function has not been fully elucidated. It is known 
A

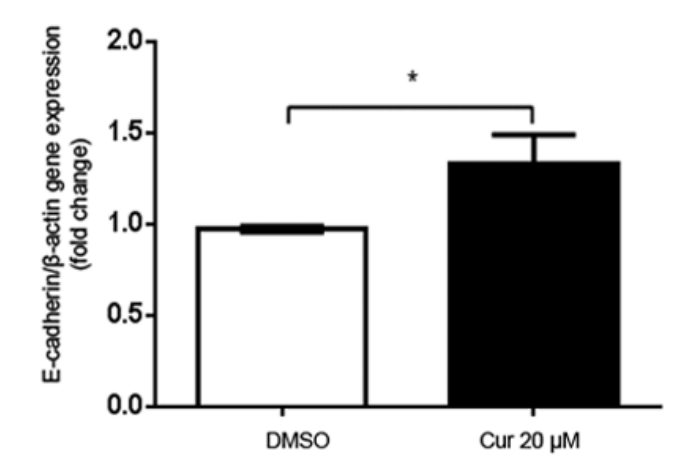

C

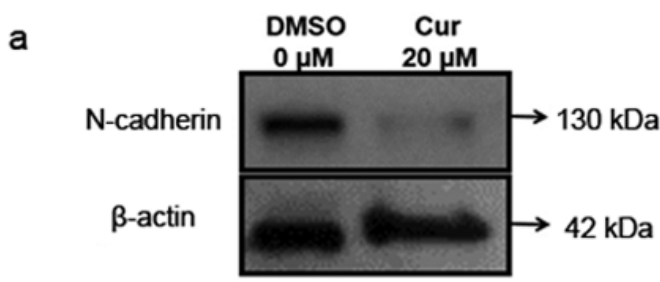

b

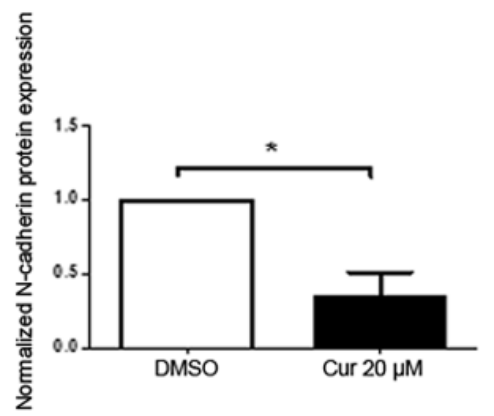

B

a

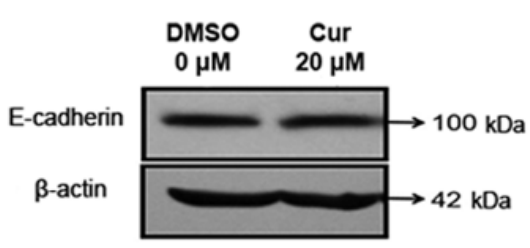

b

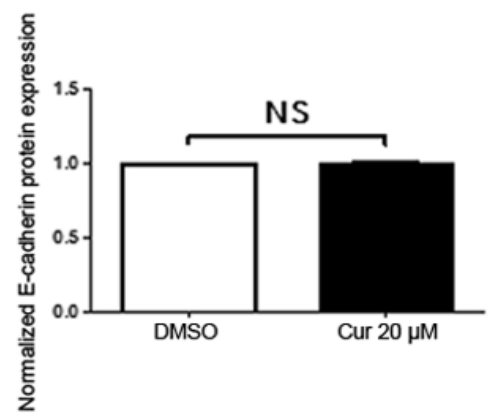

a

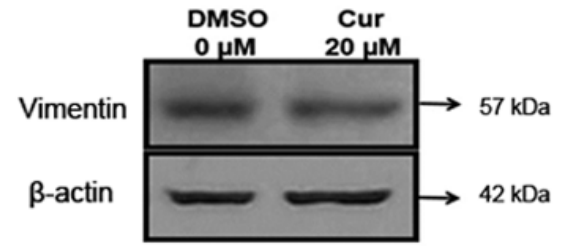

b

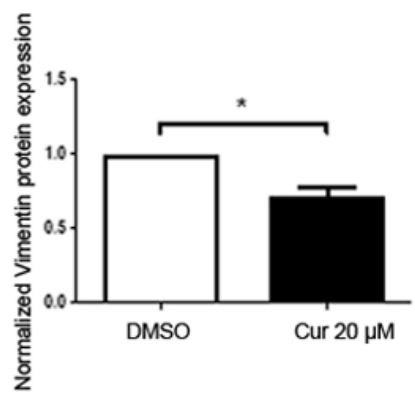

Figure 6. Effects of curcumin on epithelial-mesenchymal transition. SiHa cells were treated with DMSO or $20 \mu \mathrm{M}$ curcumin for $72 \mathrm{~h}$. (A) RNA underwent reverse transcription-quantitative polymerase chain reaction with primers for E-cadherin; findings were normalized to $\beta$-actin. Protein extracts obtained at $72 \mathrm{~h}$ were used for western blotting with antibodies against (B-a) E-cadherin, (C-a) N-cadherin, (D-a) Vimentin and $\beta$-actin. (B-b-D-b) Densitometric analysis of western blots. Data are presented as the mean \pm SEM; average of three independent experiments, conducted in triplicate. "P<0.05 (Mann-Whitney test). NS, not significant.

that human PIR is expressed at different levels in various organs, including the heart, brain, liver, kidney, lung, pancreas, placenta and skeletal muscle; the highest expression is observed in the liver and heart, whereas the lowest is in the brain and pancreas $(11,35)$. To demonstrate the participation of Pirin in the regulation of EMT, a siRNA against PIR was used; post-transfection with this siRNA, an increase in E-cadherin mRNA expression was observed. These data suggested that EMT may be regulated by Pirin. These results are similar to previously documented findings (25) in a HeLa cell model; in this previous study, Pirin was downregulated to demonstrate that it has the ability to promote EMT. In addition, these same authors concluded that Pirin regulates EMT independently to binding to BCL3-Slug (25).

The loss of E-cadherin expression is considered a crucial step in the progression of low-grade lesions to invasive carcinoma, and is a fundamental event in EMT (36). In addition, $\mathrm{N}$-cadherin stimulates cell migration and invasion. It has previously been demonstrated that aberrant expression of $\mathrm{N}$-cadherin makes cancer cells more motile and invasive (37). In addition, Vimentin is regarded as a canonical marker of EMT (38). Snail transcription factors bind to E-box consensus sequences in the E-cadherin promoter, with the help of local modifications of chromatin structure, and participate in downregulation of the transcriptional activation of the E-cadherin promoter. Slug (also known as SNAI2) is a member of the Snail family of transcriptional repressors, which is capable of suppressing E-cadherin expression and thereby triggering EMT, thus suggesting that it may act as a promoter of migration (39).

It has been reported that Snail and its family member Slug are capable of suppressing E-cadherin in epithelial cells via E-box elements in the proximal E-cadherin promoter (40). Zeb gene activation frequently occurs upon Snail activation, and Snail1 has been reported to activate Zeb1; however, Zeb is active in some tumors that lack Snail expression (41); therefore, 
A
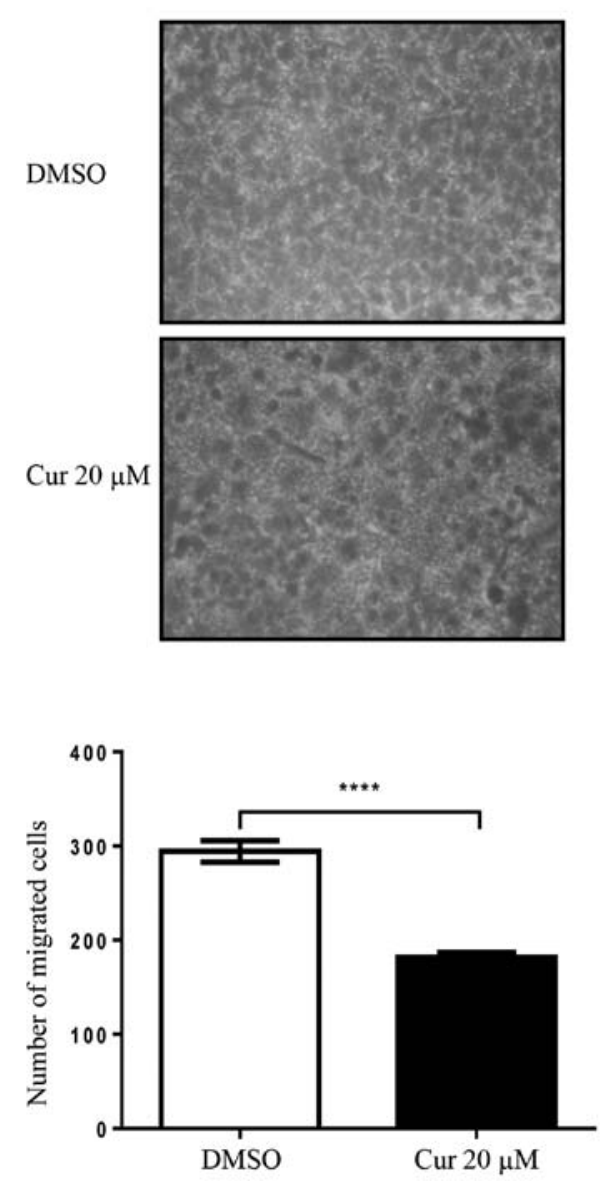

B
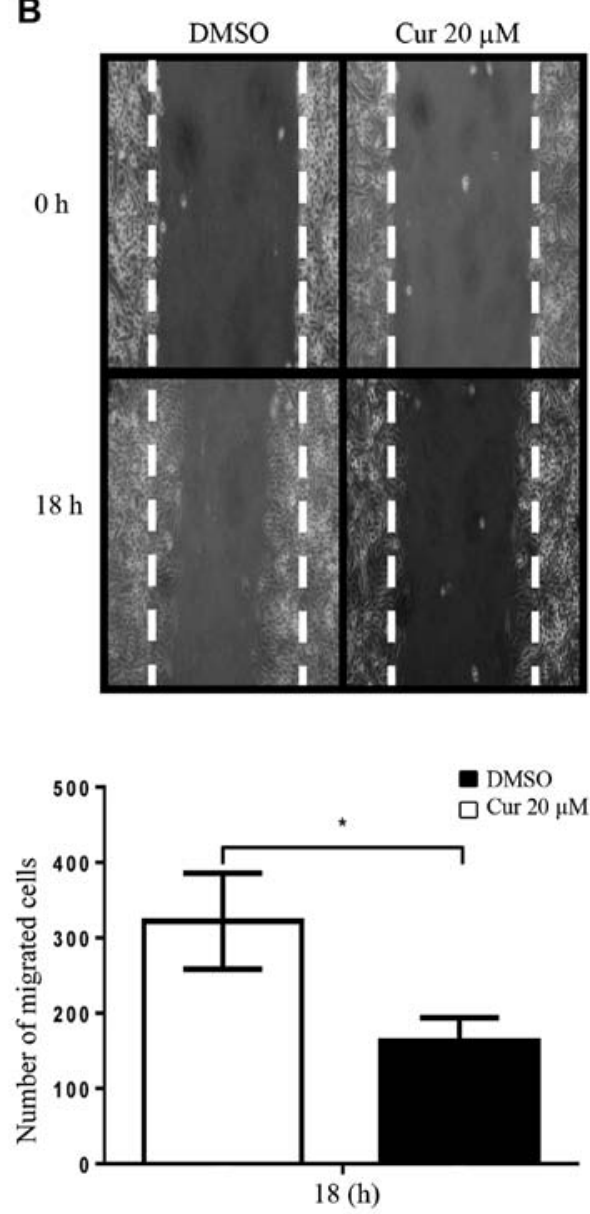

Figure 7. Effects of curcumin on cell migration. SiHa cells were treated with DMSO or curcumin (20 $\mu \mathrm{M})$ for $72 \mathrm{~h}$. (A) Migration was evaluated using a Transwell assay. Representative images (magnification, x20) and quantification of migrated cells from eight random fields are shown. (B) Migration was also evaluated using a wound healing assay. Representative images at 0 and $18 \mathrm{~h}$ post-wounding (magnification, x20) and quantification of migrated cells are shown. Data are presented as the mean \pm SEM; average of three independent experiments, conducted in triplicate. ${ }^{*} \mathrm{P}<0.05$ and ${ }^{* * * * *} \mathrm{P}<0.0001(\mathrm{Mann}-\mathrm{Whitney}$ test).

Zeb protein may be an upstream marker of EMT that can be evaluated together with E-cadherin and N-cadherin. This study demonstrated that knocking down PIR decreased the expression levels of $\mathrm{N}$-cadherin, suggesting that Pirin regulates EMT. Furthermore, it was observed that the combination of curcumin + PIR siRNA decreased N-cadherin.

These data suggested that curcumin may negatively regulate the protein expression levels of Pirin, which in turn may regulate the expression of $\mathrm{N}$-cadherin and affect the EMT. This evidence provides important information regarding the mechanism by which curcumin decreases EMT. However, these data are insufficient to deny the possibility of a Pirin-independent mechanism, by which curcumin decreases $\mathrm{N}$-cadherin and EMT. Notably, this study demonstrated that curcumin decreased the protein expression levels of Pirin and the mRNA expression levels of PIR, confirming the mechanism proposed in this study. The findings of this study also suggested that curcumin may participate in the decrease of EMT in cervical cancer cells; however, there was no alteration in the protein expression levels of E-cadherin post-exposure to curcumin, thus suggesting that other mechanisms mediated by curcumin may be involved in the regulation of the levels of E-cadherin (for example, microRNAs). In addition, the increase in Snail and Zeb1 mRNA expression contrasted the results obtained by western blotting. Previously, differences in the response of EMT markers have been reported in HeLa cells (HPV-18) (30) and in breast cancer cell lines exposed to curcumin (13).

Finally, to analyze the phenotypic alterations associated with the curcumin-mediated decrease in EMT, cell migration was evaluated by two methods. A significant decrease in migration was observed, which was similar to the findings reported by previous studies in this cellular model (30), in CaSki cells (HPV16) (6), in mice (12) and in breast cancer (13). In conclusion, curcumin decreased EMT and migration in cervical cancer cells. In addition, curcumin decreased Pirin expression and this protein was revealed to regulate EMT. These results suggested a novel mechanism by which curcumin may exerts its effect, in which the Pirin protein has an important role. Therefore, the Pirin protein may be considered an important pharmacological target in the treatment of cervical cancer.

\section{Acknowledgements}

The authors would like to thank Mr. Leodán A. Crispin (Instituto de Alta Investigación, Universidad de Tarapacá, Arica) for his technical support. 


\section{Funding}

This study was funded by Fondecyt [grant nos. 1161219 (FA) and 1151214 (HC)] and Conicyt-Fondap (grant no. 15130011).

\section{Availability of data and materials}

The datasets used and/or analyzed during the current study are available from the corresponding author on reasonable request.

\section{Authors' contributions}

VAA designed and performed the majority of the experiments, analyzed and discussed data, and approved the manuscript. DCB, JPMB, NG and JCO performed additional experiments, contributed to the discussion and approved the manuscript. HRC, JT and OL contributed to the experimental design and manuscript discussion, and provided reagents. FA and GMC designed experiments, discussed the results and wrote the manuscript. All authors read and approved the final manuscript.

\section{Ethics approval and consent to participate}

Not applicable.

\section{Patient consent for publication}

Not applicable.

\section{Competing interests}

The authors declare that they have no competing interests.

\section{References}

1. Priyadarsini KI: The chemistry of curcumin: From extraction to therapeutic agent. Molecules 19: 20091-20112, 2014.

2. Kumar P, Sulakhiya K, Barua CC and Mundhe N: TNF- $\alpha$, IL-6 and IL-10 expressions, responsible for disparity in action of curcumin against cisplatin-induced nephrotoxicity in rats. Mol Cell Biochem 431: 113-122, 2017.

3. Baghbani F, Chegeni M, Moztarzadeh F, Hadian-Ghazvini S and Raz M: Novel ultrasound-responsive chitosan/perfluorohexane nanodroplets for image-guided smart delivery of an anticancer agent: Curcumin. Mater Sci Eng C 74: 186-193, 2017.

4. Cheng A-L, Hsu C-H,Lin J-K, Hsu M-M,Ho Y-F, Shen T-S, Ko J-Y, Lin J-T, Lin B-R, Ming-Shiang W, et al: Phase I clinical trial of curcumin, a chemopreventive agent, in patients with high-risk or pre-malignant lesions. Anticancer Res 21B: 2895-2900, 2001.

5. Liu Z, Liu J, Zhao L, Geng H, Ma J, Zhang Z, Yu D and Zhong C: Curcumin reverses benzidine-induced epithelial-mesenchymal transition via suppression of ERK5/AP-1 in SV-40 immortalized human urothelial cells. Int J Oncol 50: 1321-1329, 2017.

6. Maher DM, Bell MC, O'Donnell EA, Gupta BK, Jaggi M and Chauhan SC: Curcumin suppresses human papillomavirus oncoproteins, restores $\mathrm{p} 53, \mathrm{Rb}$, and PTPN13 proteins and inhibits benzo[a]pyrene-induced upregulation of HPV E7. Mol Carcinog 50: 47-57, 2011.

7. Park W, Amin AR, Chen ZG and Shin DM: New perspectives of curcumin in cancer prevention. Cancer Prev Res (Phila) 6: 387-400, 2013

8. Panahi Y, Darvishi B, Ghanei M, Jowzi N, Beiraghdar F and Varnamkhasti BS: Molecular mechanisms of curcumins suppressing effects on tumorigenesis, angiogenesis and metastasis, focusing on NF- $\kappa \mathrm{B}$ pathway. Cytokine Growth Factor Rev 28: 21-29, 2016

9. Wright JS: Predicting the antioxidant activity of curcumin and curcuminoids. J Mol Struct 591: 207-217, 2002.
10. Scharstuhl A, Mutsaers HAM, Pennings SWC, Szarek WA, Russel FGM and Wagener FADTG: Curcumin-induced fibroblast apoptosis and in vitro wound contraction are regulated by antioxidants and heme oxygenase: Implications for scar formation. J Cell Mol Med 13: 712-725, 2009.

11. Brzóska K, Stępkowski TM and Kruszewski M: Basal PIR expression in HeLa cells is driven by NRF2 via evolutionary conserved antioxidant response element. Mol Cell Biochem 389: 99-111, 2014.

12. Zaman MS, Chauhan N, Yallapu MM, Gara RK, Maher DM, Kumari S, Sikander M, Khan S, Zafar N, Jaggi M, et al: Curcumin nanoformulation for cervical cancer treatment. Sci Rep 6: 20051, 2016.

13. Gallardo M and Calaf GM: Curcumin inhibits invasive capabilities through epithelial mesenchymal transition in breast cancer cell lines. Int J Oncol 49: 1019-1027, 2016.

14. Thiery JP, Acloque H, Huang RY and Nieto MA: Epithelial-mesenchymal transitions in development and disease. Cell 139: 871-890, 2009.

15. OMS: Cervical cancer estimated incidence, Mortality and prevalence worldwide in 2012. http://gco.iarc.fr/today/data/ pdf/fact-sheets/cancers/cancer-fact-sheets-16.pdf. Accessed March 1, 2019.

16. OMS: Human papillomavirus (HPV) and cervical cancer. 2016. http://www.who.int/mediacentre/factsheets/fs380/en/. Accessed March 1, 2019.

17. zur Hausen H: Human papillomavirus \& cervical cancer. Indian J Med Res 130: 209, 2009.

18. Senapati R, Senapati NN and Dwibedi B: Molecular mechanisms of HPV mediated neoplastic progression. Infect Agent Cancer 11: $59,2016$.

19. Niu G, Wang D, Pei Y and Sun L: Systematic identification of key genes and pathways in the development of invasive cervical cancer. Gene 618: 28-41, 2017.

20. Carrillo D, Muñoz JP, Huerta H, Leal G, Corvalán A, León O, Calaf GM, Urzúa U, Boccardo E, Tapia JC, et al: Upregulation of PIR gene expression induced by human papillomavirus E6 and E7 in epithelial oral and cervical cells. Open Biol 7: 170111, 2017.

21. LicciulliS,Luise C,Zanardi A,GiorgettiL, VialeG,LanfranconeL, Carbone R and Alcalay M: Pirin delocalization in melanoma progression identified by high content immuno-detection based approaches. BMC Cell Biol 11: 5, 2010.

22. Zeng Q, Li X, Bartlam M, Wang G, Pang H and Rao Z: Purification, crystallization and preliminary $\mathrm{X}$-ray analysis of human pirin. Acta Crystallogr D Biol Crystallogr 59: 1496-1498, 2003.

23. Pang H, Bartlam M, Zeng Q, Miyatake H, Hisano T, Miki K, Wong L-L, Gao GF and Rao Z: Crystal structure of human pirin: An iron-binding nuclear protein and transcription cofactor. J Biol Chem 279: 1491-1498, 2004.

24. Liu F, Rehmani I, Esaki S, Fu R, Chen L, de Serrano V and Liu A: Pirin is an iron-dependent redox regulator of NF- $\kappa B$. Proc Natl Acad Sci USA 110: 9722-9727, 2013.

25. Komai K, Niwa Y, Sasazawa Y and Simizu S: Pirin regulates epithelial to mesenchymal transition independently of Bcl3-Slug signaling. FEBS Lett 589: 738-743, 2015.

26. Mishra A and Das BC: Curcumin as an anti-human papillomavirus and anti-cancer compound. Future Oncol 11: 2487-2490, 2015.

27. Tennant JR: Evaluation of the trypan blue technique for determination of cell viability. Transplantation 2: 685-694, 1964.

28. Livak KJ and Schmittgen TD: Analysis of relative gene expression data using real-time quantitative PCR and the 2(-Delta Delta C(T)) method. Methods 25: 402-408, 2001.

29. Rodriguez LG, Wu X and Guan JL: Wound-healing assay. Methods Mol Biol 294: 23-29, 2005.

30. Thacker PC and Karunagaran D: Curcumin and emodin down-regulate TGF- $\beta$ signaling pathway in human cervical cancer cells. PLoS 10: e0120045, 2015.

31. Roy M and Mukherjee S: Reversal of resistance towards cisplatin by curcumin in cervical cancer cells. Asian Pac J Cancer Prev 15: 1403-1410, 2014.

32. Shao Z-M, Shen Z-Z, Liu C-H, Sartippour MR, Go VL, Heber D and Nguyen M: Curcumin exerts multiple suppressive effects on human breast carcinoma cells. Int J Cancer 98: 234-240, 2002.

33. Calaf GM, Echiburú-Chau C, Wen G, Balajee AS and Roy D: Effect of curcumin on irradiated and estrogen-transformed human breast cell lines. Int J Oncol 40: 436-442, 2012. 
34. Meissner JD: Nucleotide sequences and further characterization of human papillomavirus DNA present in the CaSki, SiHa and HeLa cervical carcinoma cell lines. J Gen Virol 80: 1725-1733, 1999.

35. Licciulli S, Cambiaghi V, Scafetta G, Gruszka AM and Alcalay M: Pirin downregulation is a feature of AML and leads to impairment of terminal myeloid differentiation. Leukemia 24: 429-437, 2010.

36. Perl AK, Wilgenbus P, Dahl U, Semb H and Christofori G: A causal role for E-cadherin in the transition from adenoma to carcinoma. Nature 392: 190-193, 1998.

37. Derycke LD and Bracke ME: N-cadherin in the spotlight of cell-cell adhesion, differentiation, embryogenesis, invasion and signalling. Int J Dev Biol 48: 463-476, 2004.

38. Satelli A and Li S: Vimentin in cancer and its potential as a molecular target for cancer therapy. Cell Mol Life Sci 68: 3033-3046, 2011.
39. Bolós V, Peinado H, Pérez-Moreno MA, Fraga MF, Esteller M and Cano A: The transcription factor Slug represses E-cadherin expression and induces epithelial to mesenchymal transitions: A comparison with Snail and E47 repressors. J Cell Sci 116: 499-511, 2003.

40. Adhikary A, Chakraborty S, Mazumdar M, Ghosh S, Mukherjee S, Manna A, Mohanty S, Nakka KK, Joshi S, De A, et al: Inhibition of epithelial to mesenchymal transition by E-cadherin up-regulation via repression of slug transcription and inhibition of E-cadherin degradation: Dual role of scaffold/matrix attachment region-binding protein 1 (SMAR1) in breast cancer cells. J Biol Chem 289: 25431-25444, 2014.

41. Wu WS, You RI, Cheng CC, Lee MC, Lin TY and Hu CT: Snail collaborates with EGR-1 and SP-1 to directly activate transcription of MMP 9 and ZEB1. Sci Rep 7: 17753, 2017. 